\title{
Evaluation of the Effects of Chitosan Hemostasis Dressings on Hemorrhage Caused by Breast Biopsy
}

\author{
Chen-Pin Chou $^{a} \quad$ Yen-Chi Wang $^{a} \quad$ Shwu Jen Chang ${ }^{b}$ Pao-Hsin Liu ${ }^{b}$ Shyh Ming Kuo \\ aDepartment of Radiology, Kaohsiung Veterans General Hospital, \\ ${ }^{b}$ Department of Biomedical Engineering, I-Shou University, Kaohsiung, Taiwan
}

\section{Keywords}

Breast biopsy $\cdot$ Hemostasis $\cdot$ Bleeding time $\cdot$ Hematoma

\section{Summary}

Background: Female breast tissue has a rich vascular supply and carries a high risk of excessive bleeding during large-core needle biopsy. It is crucial to shorten bleeding time and reduce hematoma size after the procedure. Currently, more efficient hemostatic dressings are becoming available. Material and Methods: The bleeding time and hematoma size after breast biopsy with use of either Instant Clot Pad (ICP) dressings or cotton gauze were compared. Results: ICP could attract a vast number of red blood cells and formed blood clots in about $30 \mathrm{~s}$ (in vitro blood clotting test). In clinical breast biopsy examinations, the average bleeding time with ICP was significantly reduced to about $2.9 \mathrm{~min}$ as compared to 6.4 min with cotton gauze $(p<0.005)$. The average hematoma size was also reduced with the use of ICP $\left(0.89 \mathrm{~cm}^{3}\right)$ as compared to cotton gauze $\left(1.28 \mathrm{~cm}^{3}\right)$. In patients with benign breast disease, ICP significantly reduced hematoma size. Conclusion: ICP used after breast biopsy could shorten the bleeding time in all patients, and significantly reduce the hematoma size in patients with benign compared to those with malignant breast disease.

\section{Introduction}

Breast cancer is one of the most frequent cancers in the female population. In an effort for early detection of breast cancer and reducing its mortality, far-reaching mammography screening programs have been proposed and executed

\section{Schlüsselwörter \\ Brustbiopsie · Hämostase · Blutungsdauer · Hämatom}

\section{Zusammenfassung}

Hintergrund: Das weibliche Brustgewebe ist stark vaskularisiert, und in Verbindung mit umfangreichen Hohlnadel-Biopsien kann es zu starken Blutungen kommen. Im Anschluss an eine Brustbiopsie ist es von großer Wichtigkeit, die Blutungsdauer zu verkürzen und die Hämatomgröße zu reduzieren. Wirksamere hämostatische Verbände stehen neuerdings zu diesem Zweck zur Verfügung. Material und Methoden: Die Blutungsdauer und Hämatomgröße nach Brustbiopsie mit Einsatz von entweder Instant Clot Pad (ICP)-Verbänden oder Verbandmull wurden verglichen. Ergebnisse: Das ICP-Verbandsmaterial konnte eine enorme Anzahl an Erythrozyten binden und in ca. $30 \mathrm{~s}$ Blutgerinsel bilden (In-vitro-Blutgerinnungstest). Die durchschnittliche Blutungszeit nach klinischen Brustbiopsien konnte mit ICP signifikant reduziert werden (ca. 2,9 min vs. 6,4 min mit Verbandsmull) ( $p<0,005)$. Die durchschnittliche Hämatomgröße war bei Einsatz von ICP-Verbänden ebenfalls reduziert $\left(0,89 \mathrm{~cm}^{3}\right.$ vs. $1,28 \mathrm{~cm}^{3}$ mit Verbandsmull). Bei Patienten mit gutartigen Erkrankungen der Brust konnte die Hämatomgröße mit ICP signifikant reduziert werden. Schlussfolgerung: Mit ICP konnte die Blutungsdauer bei allen Patienten verkürzt und die Hämatomgröße nach Biopsien zur Untersuchung gutartiger Erkrankungen der Brust signifikant reduziert werden.

by using current technology and devices of digital mammography as well as breast ultrasound vacuum-assisted large core biopsy devices. When breast masses or suspicious abnormal calcifications are discovered on mammogram, an image-guided breast biopsy is recommended to confirm the diagnosis. Recently, large-core vacuum-assisted stereotactic

\section{KARGER \\ Fax +497614520714 \\ Information@Karger.de}

www.karger.com (c) 2012 S. Karger GmbH, Freibur

$1661-3791 / 12 / 0073-0220 \$ 38.00 / 0$

Accessible online at:

www.karger.com/brc
Shyh Ming Kuo, Ph.D

Department of Biomedical Engineering, I-Shou University

No.8, Yida Rd., Yanchao District

Kaohsiung City 82445, Taiwan, R.O.C

Tel. +886 7 615-11007469, Fax -5150

smkuo@isu.edu.tw 
breast biopsy (VASBB) has been applied for benign and malignant breast disease $[1,2]$. However, large-core VASBB can cause several complications including breast bruising, bleeding, and hematoma formation. In general, this procedure causes active bleeding and leaves a symptomatic hematoma. Furthermore, it may disturb the cancerous cells and cause them to spread, endangering the subsequent healing process $[3,4]$.

One of the major challenges of surgical procedures that involve massive hemorrhage is to control the bleeding and promote clotting. In general, blood coagulation with the use of clamps, compression with plain dressing pads, and suturing of blood vessels is deemed inadequate. Laser coagulation procedures have also shown limited success because of extensive damage to the surrounding tissues.

Clinically, when a hemostatic dressing makes contact with a wound, it adheres to and attracts red blood cells, forming a seal that prevents further hemorrhage. Commercially available dressings are made of collagen, gelatin, alginate, and chitosan material. Chitosan (poly-(beta-1-4-D-glucosamine)) carries free amino groups alongside hydroxyl groups on the same monomer residual unit. The chitosan material exhibits a wide range of solubility with solvents of different polarity and $\mathrm{pH}$ media, and appreciable mechanical strength depending on the molecular weight and deacetylation. Its poly-positive ionic characteristics and the ease of formation of gel and membrane provide its application potential in the medical field $[5,6]$. When chitosan products encounter cells, tissues, and body fluids, they show low antigenic and aseptic responses, good compatibility to the wound site and healing process, and resistance to inflammation. Impressively, the widely spread polypositive charges of the $\mathrm{NH} 3+$ groups on the surface promote extremely fast blood clotting due to the strong interaction with the poly-negative charges on the surface of platelets and red blood cells [7, 8].

Female breast tissue has a rich vascular supply and carries a high risk of bleeding during and after interventional procedures such as biopsies. Therefore, a procedure to shorten the bleeding time and reduce hematoma formation after breast biopsy is highly desirable. In this present study, the bleeding time and hematoma size after large-core VASBB with use of either Instant Clot Pad (ICP; Bio-Sponge Technology Co., Ltd., Kaohsiung City, Taiwan) or cotton gauze were compared.

\section{Material and Methods}

\section{Material}

Chitosan dressing and cotton gauze were obtained from Bio-Sponge Technology Co., Ltd. All chemicals used for analyses in this study were of reagent grade. Human whole blood and platelet-insufficient blood were obtained from the Taiwan Blood Services Foundation (TBSF; Taipei, Taiwan).

\section{Morphology Characterization}

Scanning electron microscopy (SEM) was employed to examine the morphology of the chitosan dressing with emphasis on the porous characteristics. Prior to the SEM examination, the dressing was sputtercoated with gold and observed using a Hitachi S-2700 instrument (Hitachi Ltd., Tokyo, Japan).

\section{In Vitro Blood Clotting Test}

The chitosan dressing was cut into $1 \times 1 \mathrm{~cm}$ squares and placed into glass bottles. $0.25 \mathrm{ml}$ of blood or platelet-insufficient blood (containing the anti-coagulant citrate dextrose at a ratio of 1:6) were dispensed onto the dressing surface. The bottle containing the sample was then incubated at $37^{\circ} \mathrm{C}$. After a predetermined period, $20 \mathrm{ml}$ of distilled water were carefully added into the bottle. Red blood cells that were not entrapped in the clot were hemolyzed with distilled water, and the absorbance of the resul-
Fig. 1. Left breast calcifications seen in the mammogram of a 51-year-old woman who subsequently received VASBB and wound compression with ICP. A Clustered calcifications (arrow) found on target mammography; B Placement of VASBB device under mammography guidance; $\mathbf{C}$ No apparent blood clot found at the biopsy site (arrow) on post-biopsy mammography; D 1 week after biopsy, only traces of hematoma were found on follow-up breast ultrasound.
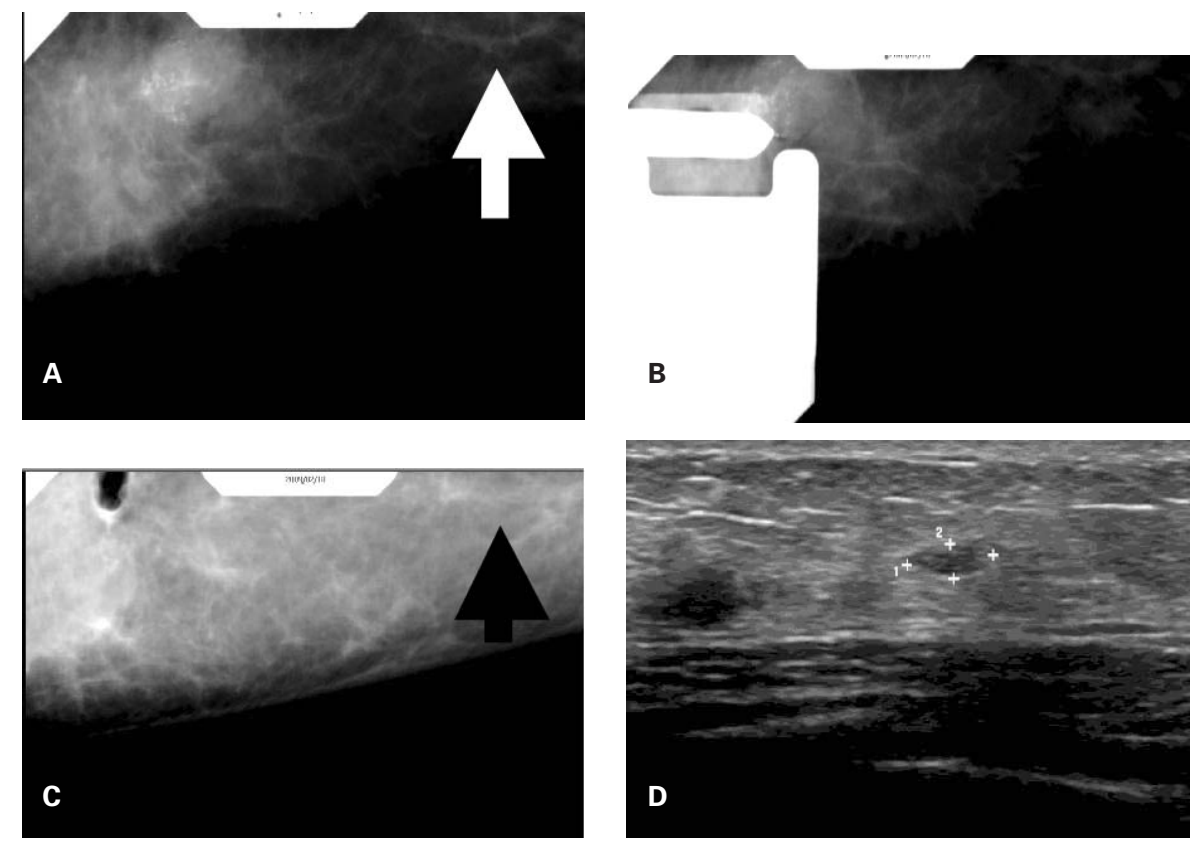
tant hemoglobin solution was measured at $540 \mathrm{~nm}$ using a UV-VIS Agilent 8453 spectrophotometer (Agilent, Santa Clara CA, USA). The absorbance of $0.25 \mathrm{ml}$ blood in $20 \mathrm{ml}$ distilled water was used as a reference value. A sample was prepared with approximately $0.5 \mathrm{ml}$ blood added to a chitosan dressing, and upon incubation at $37^{\circ} \mathrm{C}$ for $5 \mathrm{~min}$ the dressing was fixed, dried, and sputter-coated with gold for SEM examination

\section{Patients}

Data were obtained from patients who received a 10-gauge VASBB using the Vacora ${ }^{\circledR}$ Breast Biopsy System (Bard, Tempe, AZ, USA) at Kaohsiung Veterans General Hospital from October 2008 to October 2009. The institutional review board approved this retrospective review and waived patient informed consent. All biopsy procedures were carried out by the same radiologist (C.P.C.) who prior to October 2008 had experience of more than 100 VASBB cases. The mean patient age was $51.3 \pm 7.7$ years. $62 \%$ of patients were menopausal. A total of 43 women were referred to the radiology department for breast biopsy because of abnormal calcifications on mammogram. In 23 women, who underwent stereotactic breast biopsy between October 2008 and May 2009, cotton gauze was used for wound compression. In the remaining 20 women, who had a biopsy between June 2009 and October 2009, ICP was used to compress the wound. None of the 43 patients had coagulation-related diseases or used anticoagulation drugs. In the case of likely benign breast lesions classified as BI-RADS (Breast Imaging Reporting and Data System) category 3 , the procedure was undertaken based on the patient's history of breast cancer or presence of a high familial breast cancer risk. For BI-RADS category 4 or 5 lesions, classical indications for stereotactic biopsy applied. The bleeding time of the biopsy wound and the hematoma size on follow-up ultrasound examination were collected for statistical analysis.

Vacuum-Assisted Stereotactic Breast Biopsy

VASBB was applied to remove abnormal microcalcifications using mammography guidance. For stereotactic biopsy, a prone digital mammography table system (Hologic Inc., Danbury, CT, USA) was used to determine the precise location of the breast calcifications (fig. 1). Local anesthesia was provided by subcutaneous injection of $7 \mathrm{ml} 1 \%$ lidocaine and subsequent injection of $7 \mathrm{ml} 1 \%$ lidocaine with epinephrine $(1: 100,000)$ via a coaxial needle. The biopsy needle was inserted into the lesion through a $0.5 \mathrm{~cm}$ skin incision. After biopsy, we used either cotton gauze or ICP to stop the bleeding by applying manual pressure directly to the wound. The bleeding status at the biopsy site was checked every minute until the bleeding stopped completely (= bleeding time). Afterward, the wound was covered with gauze, a plastic adhesive dressing, and an elastic chest bandage for $12 \mathrm{~h}$. A breast ultrasound was performed 1 week after biopsy to locate and measure the size of the hematoma at the biopsy site. The hematoma size was calculated using the following formula: volume $=$ length $\times$ height $\times$ depth $\times 0.52$.

\section{Statistical Analysis}

The differences in bleeding time and hematoma size between the cotton gauze and ICP subgroups were analyzed for statistical significance by using the Mann-Whitney $\mathrm{U}$ test. $\mathrm{P}$ values less than 0.05 were considered statistically significant.

\section{Results}

\section{Instant Clot Pad Characteristics}

The ICP had a brown appearance and an acidulous odor. SEM indicated a porous structure with heterogeneous poresize distribution and penetrating pores both on the surface
Fig. 2. Scanning electron microscopic images of ICP:

A Surface;

B Cross-section.

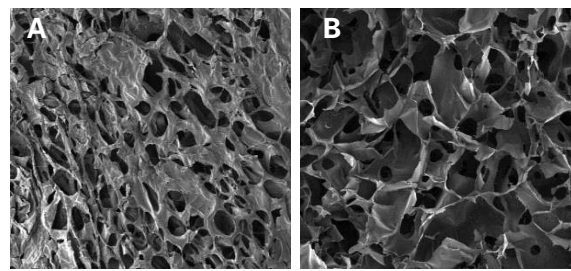

Fig. 3. Blood clotting rates with ICP for normal whole blood and platelet-insufficient blood.
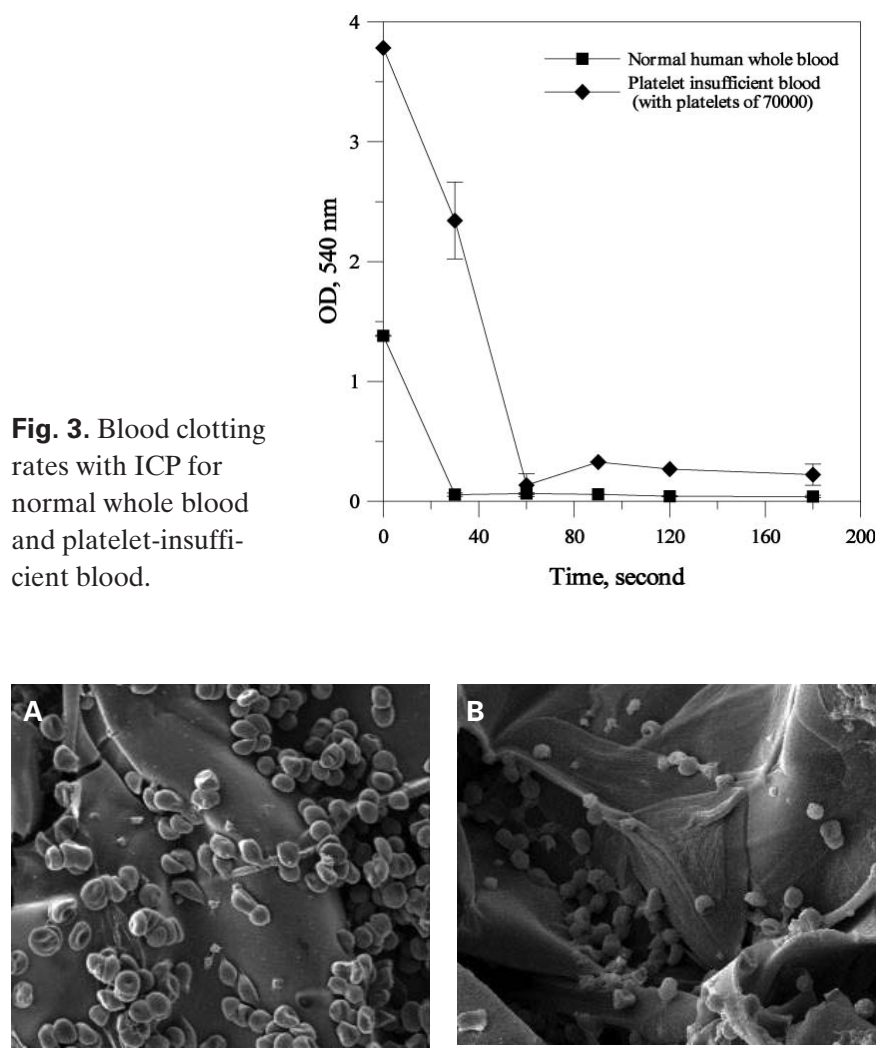

Fig. 4. Scanning electron microscopic images of $\mathbf{A}$ human normal whole blood, and B platelet-insufficient blood on ICP after $60 \mathrm{~s}$ of absorption.

and the cross-sectional view (fig. 2). These pores were approximately $200-250 \mu \mathrm{m}$ in diameter.

\section{In Vitro Blood Clotting Test}

Human whole blood containing either a normal or decreased number of platelets $(70,000$ platelets $/ \mathrm{ml})$ was dripped onto the ICP for 30-180 s. The absorbance of the hemoglobin-containing solution was measured, with a high absorbance value indicating a slower clotting rate. As shown in figure 3, ICP yielded lower absorbance values for the normal whole blood sample and formed clots after about $30 \mathrm{~s}$, whereas the platelet-insufficient blood formed clots on the pad after about $60 \mathrm{~s}$. SEM observations revealed that the red blood cells could form aggregates on the pad for both the normal whole blood and platelet-insufficient blood. However, clusters of decreased aggregates or clots were formed for the platelet-insufficient blood (fig. 4). 


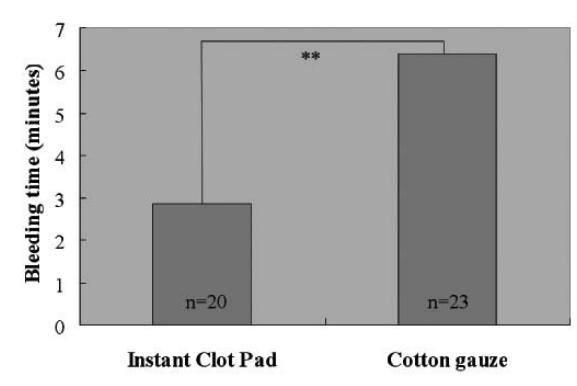

Fig. 5. Statistical results of the bleeding time between the cotton gauze and ICP subgroups. The influence on bleeding time was highly significant $(* * \mathrm{p}<0.005)$.
Fig. 6. Statistical results of the hematoma size between the cotton gauze and ICP subgroups (NS = not significant).

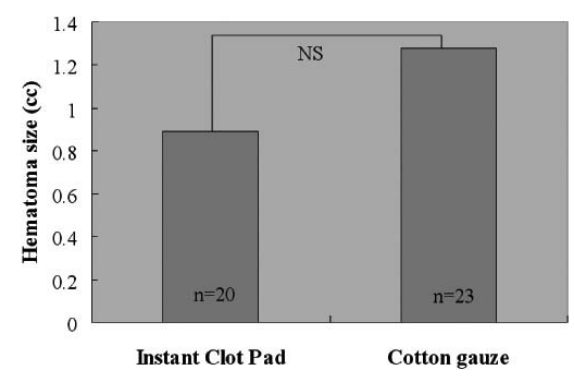

Table 1. Mammographic characteristics observed in 43 patients

\begin{tabular}{lc}
\hline Clinical data & Patients, $\mathrm{n}(\%)$ \\
\hline Menstruation status & $27(62)$ \\
Menopausal & $16(38)$ \\
Premenopausal & \\
BI-RADS category & $3(8)$ \\
3 (probably benign) & $39(90)$ \\
4 (suspicious abnormality) & $1(2)$ \\
5 (highly suggestive of malignancy) & $2(5)$ \\
Breast density category & $9(20)$ \\
Type I (fatty) & $19(45)$ \\
Type II (scattered densities) & $13(30)$ \\
Type III (heterogeneously dense) & \\
Type IV (extremely dense) & $28(66)$ \\
Pathology & $3(7)$ \\
Benign & $9(20)$ \\
FCD & $3(7)$ \\
ADH & \\
Malignant & \\
DCIS & \\
IDC & \\
\hline BI-RADS = Breast Imaging Reporting and Data System; \\
FCD = fibrocystic disease; ADH = atypical ductal hyperplasia; \\
DCIS = ductal carcinoma in situ; IDC = invasive ductal carcinoma. \\
\hline
\end{tabular}

Correlation between Mammographic Findings and Histology Among the 43 mammographic abnormalities, 31 (73\%) corresponded to benign tumors (28 fibrocystic disease and 3 atypical ductal hyperplasia), and 12 (27\%) corresponded to malignant tumors (9 ductal carcinoma in situ and 3 invasive ductal carcinoma). The distribution of histological findings in the 43 patients is summarized in table 1 .

Statistical Analysis of the Bleeding Time and Hematoma Size The average biopsy bleeding time when cotton gauze was used to stop the bleeding $(\mathrm{n}=23)$ was $6.4 \mathrm{~min}$ (range 1-15 $\min )$. In the ICP group $(n=20)$, the average bleeding time decreased significantly to 2.9 min (range 1-15 min) (table 2). Hence, bleeding time was statistically different between the cotton gauze and ICP group $(\mathrm{p}<0.005)$ (fig. 5). The average hematoma size in patients treated with cotton gauze and ICP was $1.28 \mathrm{~cm}^{3}$ (range $0.006-5.24 \mathrm{~cm}^{3}$ ) and $0.89 \mathrm{~cm}^{3}$ (range $0.001-3.44 \mathrm{~cm}^{3}$ ), respectively. The difference was not statistically significant $(\mathrm{p}=0.4431)$ (fig. 6). However, hematoma sizes in the ICP subgroups of benign $(\mathrm{n}=13)$ and malignant $(n=7)$ breast disease were evidently different $(\mathrm{p}=0.0071)$ (table 3$)$. In the cotton gauze subgroup,
Table 2. Bleeding time and hematoma size after breast biopsy (mean \pm standard deviation)

\begin{tabular}{lll}
\hline & $\begin{array}{l}\text { Instant Clot Pad } \\
(\mathrm{n}=20)\end{array}$ & $\begin{array}{l}\text { Cotton Gauze } \\
(\mathrm{n}=23)\end{array}$ \\
\hline Bleeding time, $\min$ & $2.85 \pm 3.59$ & $6.39 \pm 4.01$ \\
Hematoma size, $\mathrm{cm}^{3}$ & $0.89 \pm 1.09$ & $1.28 \pm 1.53$ \\
\hline
\end{tabular}

Table 3. Mann-Whitney $U$ test for hematoma size in benign and malignant breast disease subgroups

\begin{tabular}{lll}
\hline & Hematoma size ${ }^{\mathrm{a}} \mathrm{cm}^{3}$ & $\mathrm{p}^{\mathrm{b}}$ \\
\hline Instant Clot Pad & & 0.007058 \\
$\quad$ Benign breast disease $(\mathrm{n}=13)$ & $0.379 \pm 0.480$ & \\
$\quad$ Malignant breast disease $(\mathrm{n}=7)$ & $1.826 \pm 1.313$ & \\
Cotton gauze & & 0.823065 \\
$\quad$ Benign breast disease $(\mathrm{n}=18)$ & $1.335 \pm 1.563$ & \\
$\quad$ Malignant breast disease $(\mathrm{n}=5)$ & $1.074 \pm 1.548$ & \\
\hline${ }^{\mathrm{a}}$ Mean \pm standard deviation. & & \\
${ }^{\mathrm{b}}$ Statistical significance at $\mathrm{p}<0.05$. & & \\
\hline
\end{tabular}

hematoma size did not vary significantly between patients with benign $(n=18)$ and those with malignant $(n=5)$ breast disease $(\mathrm{p}=0.8231)$.

\section{Discussion}

Detection of abnormal microcalcifications is important for early breast cancer diagnosis. Calcifications on mammogram may need further imaging work-up or biopsy to determine the nature of the pathology. The advantages of VASBB are that it offers a larger number of specimens than traditional large-core needle biopsy, yet with similar accuracy as surgical biopsy and less false-negative biopsy results. Furthermore, VASBB, a minimally invasive procedure, helps in the diagnosis of abnormal breast calcifications and non-palpable breast lesions. Complications of VASBB include bleeding, hematoma, infection, and skin bruising. A small amount of hematomas can be located at the prior biopsy area of calcifications and thus be helpful during subsequent breast cancer surgery. However, large and extensive hematomas can cause difficulties with tumor localization during surgery and migra- 
tion of tissue markers. However, breast biopsy lesions are superficial, and bleeding can be stopped by direct manual compression.

Statistical analyses were performed for 43 patients with benign and malignant breast calcifications. We found ICP had no significant effect on reducing the hematoma size compared with cotton gauze. However, ICP showed significant differences in terms of homeostasis between patients with benign and malignant breast disease, with reduction in hematoma size by $72 \%$ in patients with benign calcifications. Furthermore, ICP significantly reduces biopsy bleeding time. Following breast biopsy, direct pressure with cotton gauze may be associated with slow oozing of blood from the wound and prolonged procedure time. With the use of ICP, however, forma- tion of a stable thrombus and prevention of slow oozing can be achieved. In the clinical setting, use of ICP can reduce the waiting time for a complete stop of bleeding by $55 \%$. It also can alleviate complications due to recurrent bleeding during wound dressing and recovery. In summary, ICP significantly shortened the biopsy bleeding time in routine breast biopsy and reduced the hematoma size in patients with benign breast disease.

\section{Disclosure Statement}

None of the authors have any conflicts of interest to declare.

\section{References}

1 Schulz-Wendtland R, Krämer S: Breast imaging and interventional procedures - the basis for oncoplastic breast surgery. Breast Care 2007;2:288-296.

2 Salem C, Sakr R, Chopier J, Marsault C, Uzan S, Daraï E: Accuracy of stereotactic vacuum-assisted breast biopsy with a 10-gauge hand-held system. Breast 2009;18:178-182.

3 Inui H, Watatani M, Hashimoto Y, Hojo T, Hirai K, Yamato M, Fujishima M, Azumi T, Shiozaki H Hematoma-directed and ultrasound-guided breast-conserving surgery for nonpalpable breast cancer after Mammotome biopsy. Surg Today 2008;38:279-282.
4 Zografos GC, Zagouri F, Sergentanis TN, Koulocheri D, Flessas I, Provatopoulou X, Kalogera E, Michalopoulos NV, Bramis J, Gounaris A: Hematoma after vacuum-assisted breast biopsy: are interleukins predictors? Onkologie 2009:32:395-397.

5 Kuo SM, Chang SJ, Chen TW, Kuan TC: Guided tissue regeneration for using a chitosan membrane: an experimental study in rats. J Biomed Mater Res 2006;76A:408-415.
6 Horio T, Ishihara M, Fujita M, Kishimoto S, Kanatani Y, Ishizuka T, Nogami Y, Nakamura S, Tanaka Y, Morimoto Y, Maehara T: Effect of photocrosslinkable chitosan hydrogel and its sponges to stop bleeding in a rat liver injury model. Artif Organs 2010;34:342-347.

7 Kranokpiraksa P, Pavcnik D, Kakizawa H, Uchida BT, Jeromel M, Keller FS, Rosch J: Hemostatic efficacy of chitosan-based bandage for closure of percutaneous arterial access sites: an experimental study in heparinized sheep model. Radiol Oncol 2010;44:86-91.

8 Chou TC, Fu E, Wu CJ, Yeh JH: Chitosan enhances platelet adhesion and aggregation. Biochem Biophys Res Commun 2003;302:480-483. 